\title{
Dual Trigger with Gonadotropin-releasing Hormone Agonist and Human Chorionic Gonadotropin Improves Live Birth Rate for Women with Expected Normal Ovarian Response in Gonadotropin Releasing Hormone Antagonist Cycles: Retrospective Study
}

\author{
(1] Firat TÜLEK ${ }^{\mathrm{a}, \mathrm{b}}$, () Alper KAHRAMAN ${ }^{\mathrm{c}}$ \\ ${ }^{\mathrm{a}}$ Clinic of Obstetrics and Gynecology, Memorial Ataşehir Hospital, İstanbul, TURKEY \\ ${ }^{b}$ Department of Midwifery, Üsküdar University Faculty of Health Sciences, İstanbul, TURKEY \\ ${ }^{\mathrm{c}}$ Clinic of Obstetrics and Gynecology, Haseki Training and Research Hospital, İstanbul, TURKEY
}

\begin{abstract}
Objective: To evaluate and compare cycle outcomes following triggering final oocyte maturation with dual trigger of concomitant gonadotropin-releasing hormone $(\mathrm{GnRH})$ agonist and human chorionic gonadotropin (hCG) administration versus hCG alone for women with expected normal ovarian response that underwent antagonist cycles with intracytoplasmic sperm injection (ICSI). Material and Methods: Women with expected normal ovarian response that underwent GnRH antagonist cycles with ICSI between January 2010 and April 2020 were evaluated in this retrospective cohort study. A total of 2,443 patients were included. Dual trigger was used for oocyte maturation in 637 cycles whereas hCG alone was used for triggering in 1,806 women. Cycles with dual trigger were assigned to study group and cycles with hCG alone are taken as controls. Results: Number of retrieved oocytes (14.08 \pm 3.58 vs. $13.15 \pm 3.61)$, number of metaphase 2 oocytes ( $9.77 \pm 3.08$ vs. $8.06 \pm 3.14)$, fertilization rate $(0.75 \pm 0.19$ vs. $0.69 \pm 0.19)$, implantation rate $(0.43 \pm 0.48$ vs. $0.35 \pm 0.50)$ and clinical pregnancy rate $(49.9 \%$ vs. $40.6 \%)$ were significantly higher in dual trigger group in comparison to hCG alone group. Higher number of good quality embryos were obtained in dual trigger group $(85.7 \%$ vs. $76.3 \%)$. Live birth rate was significantly increased in dual trigger group in comparison to hCG only trigger group $(45.1 \%$ vs. $36.7 \%)$. Multivariate logistic regression analysis showed dual trigger is a significant factor in predicting live birth deliveries (odds ratio 1.426, 95\% confidence interval 1.185-1.716). Conclusion: Dual-triggering appears to improve embryo quality, increase implantation rates, clinical pregnancy rates and live birth rates in women with expected normal ovarian response that underwent GnRH antagonist cycles.
\end{abstract}

Keywords: Live birth; fertilization in vitro; gonadotropin-releasing hormone; infertility, female; antagonists-inhibitors

Human chorionic gonadotropin (hCG) is used as an oocyte triggering agent in in-vitro fertilization (IVF) cycles as a substitute for luteinizing hormone (LH) to trigger granulosa cell luteinization, resumption of meiosis and final oocyte maturation. However, hCG administration is associated with risk of ovarian hyperstimulation syndrome (OHSS) development. Preventive measures like withholding oocyte triggering or cycle cancellation are both grueling and financially costly hence creates frustration on patients. ${ }^{1}$ Therefore, alternative methods to prevent
OHSS without compromising IVF success have been investigated. Introduction of gonadotropin-releasing hormone $(\mathrm{GnRH})$ antagonist cycles allows the use of GnRH agonists for final oocyte maturation triggering. Triggering of oocyte maturation with a $\mathrm{GnRH}$ agonist agent was first proposed by Gonen et al. in 1990 and suggested as a measure to prevent OHSS. ${ }^{2}$

$\mathrm{GnRH}$ agonists induce release of gonadotropins form pituitary gland with a flare up effect. Although hCG and LH bind to same LH receptor, these 2 molecules create different effects on downstream signal-

Correspondence: Firat TÜLEK

Clinic of Obstetrics and Gynecology, Memorial Ataşehir Hospital, İstanbul, TURKEY

E-mail: firattulek@yahoo.com

Peer review under responsibility of Journal of Clinical Obstetrics \& Gynecology. 
ing pathways. ${ }^{3}$ Moreover, GnRH agonists are known to induce both $\mathrm{LH}$ and follicle stimulating hormone (FSH) surges with their flare-up effects with a shorter duration in comparison to hCG. ${ }^{4}$ This pattern of gonadotropin surge more closely mimic the ovulatory changes in natural menstrual cycles. ${ }^{5}$ Thus GnRH agonist triggering effectively reduces the rate of OHSS and proposed as a measure to prevent OHSS in highrisk patients. ${ }^{6}$ Besides preventing OHSS, GnRH agonist administration has been shown to increase endometrial receptivity probably by direct effects on endometrial cells, increase oocyte maturation rates and increase embryo quality. ${ }^{711}$ All these advantages makes GnRH agonist triggering seem like an appealing choice to increase IVF success rates not only in patients with high risk of OHSS but also in all women with infertility. However due to the shorter duration and smaller amplitude of gonadotropin surge, $\mathrm{GnRH}$ agonist triggering alone, fails to sufficiently support corpus luteum functions and leads to higher rates of early pregnancy losses and lower rates of ongoing pregnancies in fresh embryo transfer cycles. ${ }^{6}$ Intensive luteal support and supplementing GnRH agonist with hCG were proposed to overcome this disadvantage. ${ }^{12,13}$ To benefit from advantages of both GnRH agonist and hCG, triggering of final oocyte maturation with concomitant administration of GnRH agonist and hCG was described by Shapiro et al. and termed as dual-triggering. ${ }^{13}$ There are meagre number of studies in literature evaluating the effects of dual triggering on IVF outcomes in various subgroups of patients such as hyper-responder, normo-responder

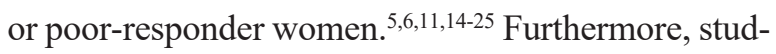
ies reporting live birth rates, the ultimate goal of infertility treatment, in dually triggered women with expected normal ovarian response are even scarcer. 5,6,11,21,23,25 Therefore, current amount of evidence is not adequate to recommend or argue against the use of dual triggering particularly in women with predicted normal ovarian response. ${ }^{26}$

In an intention to standardize studies and to provide more functional data to guide the establishment of clinical management strategies, POSEIDON study group re-identified and stratified "low prognosis" women due to various drawbacks of former classification systems. ${ }^{27}$
Here we conducted this study to evaluate the effects of dual-triggering on IVF outcomes of women classified as normal prognosis or expected normal ovarian response, based on POSEIDON classification system.

\section{MATERIAL AND METHODS}

This retrospective cohort study was conducted at a university-affiliated infertility center (Memorial Ataşehir Hospital affiliated with Üsküdar University) in İstanbul. Records of patients that underwent intracytoplasmic sperm injection (ICSI) following a GnRH antagonist cycle between January 2010 and April 2020 were analyzed. Data were compiled from electronic medical records. Ethics approval for this study was received from Ethics Committee of Üsküdar University at 28.06.2021 (Approval number: 61351342/June 2021-63). Study protocol is in accordance with the "Declaration of Helsinki-Ethical Principles for Medical Research Involving Human Subjects" and the need for consent was omitted by ethics committee due to the retrospective design. Patients with high $\left(>30 \mathrm{~kg} / \mathrm{m}^{2}\right)$ or low $\left(<18 \mathrm{~kg} / \mathrm{m}^{2}\right)$ body mass index (BMI), patients with additional endocrine co-morbidities namely, diabetes mellitus, thyroid dysfunction, hyperprolactinemia, congenital adrenal hyperplasia, Addison disease, Cushing syndrome, patients with corrected or present uterine anomalies, patients with infertility due to azoospermia and women with low prognosis due to POSEIDON classification at the initiation of treatment were excluded from the study. Freeze-all cycles were also excluded. Women that antral follicle count $\geq 5$, anti-Mullerian hormone $\geq 1.2 \mathrm{ng} / \mathrm{mL}$, either have no other previous IVF attempts or that at least 10 oocytes were retrieved in all other previous IVF cycles were included in the study. Among these women that underwent GnRH antagonist cycles, cycle outcomes of dual-triggering and hCG-only triggering were compared. By this way all of the expected or unexpected poor ovarian responders defined by POSEIDON group 1, 2, 3, or 4 were excluded from the study.

Controlled ovarian stimulation was initiated on the $2^{\text {nd }}$ day of menstrual cycle. Recombinant FSH (rFSH) (Gonal F; Serono, Istanbul, Turkey), human menopausal gonadotropin (Merional, IBSA, Istanbul, 
Turkey; Menopur, Ferring, Istanbul, Turkey) or combination of recombinant LH and $\mathrm{rFSH}$ (Pergoveris; Serono, Istanbul, Turkey) is used for ovarian stimulation on practitioner's choice. Patients are monitored during stimulation for follicular growth with serial transvaginal ultrasounds. Serum estradiol and progesterone levels were assessed at the day of oocyte maturation triggering. Gonadotropin doses are titrated in accordance with each patient's follicular growth. Once the leading follicle is observed to reach a diameter of 12-14 mm, GnRH antagonist (Cetrotide $0.25 \mathrm{mg}$, Merck-Serono, Istanbul, Turkey) injections commenced to suppress premature LH peak and continued to the day of oocyte maturation triggering. Oocyte maturation is induced when follicles have reached a diameter of $18 \mathrm{~mm}$. In dual-triggering group, concomitant injections of GnRH agonist of 0.2 mg triptorelin acetate, (Gonapeptyl $0.1 \mathrm{mg}$, Ferring, Istanbul, Turkey) and $250 \mathrm{mcg}$ recombinant hCG (Ovitrelle, Serono, Istanbul, Turkey) were used for final oocyte maturation. In hCG-only group, $250 \mathrm{mcg}$ recombinant hCG (Ovitrelle, Serono, Istanbul, Turkey) injections were used alone to induce final oocyte maturation. Oocytes are retrieved under transvaginal ultrasound guidance 35-36 hours after oocyte maturation triggering. Fertilization was carried out by ICSI. Embryo quality was graded according to the Society for Assisted Reproductive Technology (SART) grading system. ${ }^{28}$ In accordance with the SART grading system, Grade 1 embryos are referred as good quality embryos, Grade 2 embryos are referred as fair quality embryos and Grade 3 embryos are referred as poor quality embryos in this study. Day 3 or day 5 embryos are transferred by using an embryo transfer catheter under guidance of abdominal ultrasonography, by phsicians' preference due to individual condition of each patient and embryo cohort. A maximum of 2 embryos were transferred in each attempt. Luteal phase support with intravaginal progesterone is initiated in every patient with either $200 \mathrm{mg}$ Lutinus twice a day or with $200 \mathrm{mg}$ Progestan 3 times a day (Lutınus vaginal tablets, Ferring Pharmaceuticals, Istanbul,Turkey; Progestan Soft Capsules, Kocak Farma, Istanbul,Turkey) and continued through $8^{\text {th }}-10^{\text {th }}$ gestational weeks.

Women with expected normal ovarian response that underwent ICSI following a GnRH antagonist cycle with dual-triggering within the selected period of time are assigned to the study group. Women with expected normal ovarian response that underwent ICSI following a GnRH antagonist cycle with hCGonly triggering within the selected period of time are constituted the control group.

Primary outcome of this study was determined as live birth rates. Secondary outcomes are number of oocytes retrieved, number of metaphase 2 (M2) oocytes, oocyte maturation rates (number of M2 oocytes/number of retrieved oocytes), number of 2 pronuclear (2PN) embryos, fertilization rates (number of 2PN embryos/number of M2 oocytes), quality of embryos, progression to blastocyst rates, implantation rates (gestational sacs observed/transferred embryos), clinical pregnancy rates, cycle cancellation rates and miscarriage rates. In terms of outcomes associated with implantation and pregnancy, only results of fresh embryo transfers were included in this study. Outcome parameters were defined in accordance with a previously published consensus. ${ }^{29}$

Statistical analysis was conducted by IBM SPSS 23 (evaluation version). Descriptive statistics were expressed as mean \pm standard deviations for normally distributed data. Categorical variables were expressed as numbers and percentages (\%). Significance of differences between means were assessed with Student's $t$ test. Categorical variables were assessed with Pearson's chi-squared test or Fisher's exact test. $p$ values $<0.05$ are considered as significant. Multivariate linear regression analysis with backward elimination was performed to identify independent variables effecting implantation rates. Multivariate logistic regression analysis was performed to predict live births.

\section{RESULTS}

Following exclusion of ineligible subjects, a total of 637 women with expected normal ovarian response were found to underwent GnRH antagonist cycles that final oocyte maturation was induced by concomitant injections of GnRH agonist and hCG. Whereas 1,806 women were found to underwent $\mathrm{GnRH}$ antagonist cycles that oocyte maturation was induced by hCG administration alone within the selected period of time. Dual-triggering and hCG-only 
groups were found similar in terms of mean age and mean BMI ( $p=0.053$ and $p=0.372$ respectively). Infertility causes in study population were as follows with decreasing prevalence: mild male factor infertility, anovulation, unexplained infertility, tubal factor infertility, endometriosis and combined infertility. In dual triggering group, $15.2 \%$ of embryo transfers were day 3 transfers and $84.8 \%$ of them were day 5 embryo transfers. In hCG-only group, $18.7 \%$ of embryo transfers were day 3 embryo transfers and $81.3 \%$ were day 5 transfers. No significant differences were found in terms of day of embryo transfers. Of women in dual triggering group, $74.1 \%$ were received $3 \times 200 \mathrm{mg}$ oral progesterone for lueat 1 phase support and $25.8 \%$ of them received $2 \times 200 \mathrm{mg}$ intravaginal progesterone. In hCG-only group, $73.2 \%$ of patients received $3 \times 200 \mathrm{mg}$ oral progesterone and $26.8 \%$ of them received $2 \times 200 \mathrm{mg}$ intravaginal progesterone. No significant differences were found in terms of luteal phase support methods received by patients. No significant differences were found between 2 groups in distribution of prevalence of etiologic factors within patients $(\mathrm{p}=0.995)$. Baseline characteristics of dual-triggering group and hCG-only group were given in Table 1.

Required gonadotropin doses, length of ovarian stimulation, peak estradiol levels, peak progesterone levels and cycle cancellation rates were similar in dual-triggering and hCG-only triggering groups. Mean endometrial thickness at the day of embryo transfer, number of retrieved oocytes, oocyte maturation rates, fertilization rates, quality of obtained embryos, implantation rates and clinical pregnancy rates were all found significantly higher in dual-triggering group in comparison to hCG-only group. Multiple pregnancy rate was not significantly different among dual-triggering and hCG-only groups. Although a trend towards lower miscarriage rates in dual-triggering group was observed, the difference was not statistically significant compared to hCGonly group. A significant increase in live birth rate is found in dual-triggering group in comparison to controls. Comparison of IVF cycle outcomes in women that oocyte maturation is induced by dualtriggering or by hCG triggering alone were summarized in Table 2.
TABLE 1: Baseline characteristics of dual-triggering and hCG-only groups.

\begin{tabular}{|lccc|}
\hline & Dual-triggering group & hCG-only group & p value \\
\hline Number of cycles & 637 & 1,806 & \\
\hline Age (years) & $32.34 \pm 4.52$ & $31.98 \pm 4.84$ & 0.053 \\
BMI & $24.92 \pm 2.99$ & $25.04 \pm 3.05$ & 0.372 \\
\hline Infertility etiology & & & \\
- Mild male factor & $191(30 \%)$ & $541(30 \%)$ & \\
- Anovulation & $151(23.7 \%)$ & $425(23.5 \%)$ & \\
- Tubal factor & $88(13.8 \%)$ & $251(13.9 \%)$ & \\
" Endometriosis & $47(7.4 \%)$ & $132(7.3 \%)$ & \\
- Combined & $41(6.4 \%)$ & $106(5.9 \%)$ & \\
- Unexplained & $119(18.7 \%)$ & $351(19.4 \%)$ & 0.995 \\
\hline
\end{tabular}

hCG: Human chorionic gonadotropin; BMl: Body mass index.

Multivariate linear regression analysis with backward elimination was performed to identify independent variables effecting implantation rates. Before applying multivariate logistic regression analysis, univariate analysis were performed and parameters with a $p<0.20$ were interpreted as candidates for multivariate analysis and tested with backward method to evaluate significance of differences. Factors found as candidates in univariate regression analysis and included in the multivariate logistic regression analysis were age, endometrial thickness, number of retrieved oocytes, number of M2 oocytes, number of 2PN embryos, embryo quality and triggering method. Age $(\mathrm{p}<0.001)$, number of $2 \mathrm{PN}$ embryos $(\mathrm{p}<0.001)$, embryo quality $(\mathrm{p}<0.001)$ were found as independent determinants of implantation rate (Table 3). Multivariate logistic regression analysis was performed to predict live births. Following a univariate analysis, parameters with a $\mathrm{p}<0.20$ were interpreted as candidates for multivariate analysis and tested with backward method to evaluate significance of differences. Factors included in the model were age, BMI, endometrial thickness, fertilization rate, number of retrieved oocytes, maturation rate, number of transferred embryos and progression to blastocyst rate and dual triggering. Among these parameters, age [odds ratio (OR) $0.953,95 \%$ confidence interval (CI): 0.936-0.970], fertilization rate (OR: 3.237, 2.074-5.053), maturation rate (OR: $1.786,95 \%$ CI: $1.115-2.860$ ), and dual trigger (OR: $1.426,95 \%$ CI: $1.185-1.716$ ) were found as significant predictors of live birth deliveries (Table 4). 
TABLE 2: Comparison of IVF cycle outcomes in dual-triggering and hCG-only triggering groups.

\begin{tabular}{|c|c|c|c|}
\hline & $\begin{array}{c}\text { Dual-triggering } \\
\text { group }\end{array}$ & $\begin{array}{l}\text { hCG-only } \\
\text { group }\end{array}$ & $p$ value \\
\hline Number of cycles & 637 & 1,806 & \\
\hline Required gonadotropin doses (IU) & $2529.96 \pm 744.67$ & $2480.98 \pm 715.74$ & 0.105 \\
\hline Lenght of stimulation (days) & $9.67 \pm 1.59$ & $9.52 \pm 1.35$ & 0.064 \\
\hline Estradiol level (pg/mL) & $1965.83 \pm 716.92$ & $1933.69 \pm 603.42$ & 0.490 \\
\hline Progesterone level (ng/mL) & $0.64 \pm 0.31$ & $0.68 \pm 0.31$ & 0.108 \\
\hline Endometrial thickness (mm) & $10.80 \pm 1.96$ & $10.50 \pm 1.89$ & 0.001 \\
\hline Number of retrieved oocytes per cycle & $14.08 \pm 3.58$ & $13.15 \pm 3.61$ & $<0.001$ \\
\hline Number of metaphase 2 oocytes per cycle & $9.77 \pm 3.08$ & $8.06 \pm 3.14$ & $<0.001$ \\
\hline Maturation rate per cycle & $0.70 \pm 0.16$ & $0.62 \pm 0.18$ & $<0.001$ \\
\hline Number of 2 pronuclear embryos per cycle & $7.39 \pm 4.0$ & $5.60 \pm 2.76$ & $<0.001$ \\
\hline Fertilization rate per cycle & $0.75 \pm 0.19$ & $0.69 \pm 0.19$ & $<0.001$ \\
\hline Blastocyst progression rate & $0.45 \pm 0.20$ & $0.45 \pm 0.21$ & 0.237 \\
\hline \multicolumn{4}{|l|}{ Quality of obtained embryos } \\
\hline - Good & $1991(85.7 \%)$ & $3346(76.3 \%)$ & \\
\hline - Fair & $252(10.9 \%)$ & $706(16.1 \%)$ & \\
\hline - Poor & $79(3.4 \%)$ & $333(7.6 \%)$ & $<0.001$ \\
\hline Number of transferred embryos & $1.45 \pm 0.52$ & $1.47 \pm 0.51$ & 0.405 \\
\hline \multicolumn{4}{|l|}{ Quality of transferred embryos } \\
\hline - Good & $778(84.2 \%)$ & $1925(75.4 \%)$ & \\
\hline - Fair & $117(12.7 \%)$ & $430(16.8 \%)$ & \\
\hline - Poor & $29(3.1 \%)$ & $199(7.8 \%)$ & $<0.001$ \\
\hline Number of cryopreserved embryos & $2.21 \pm 1.50$ & $1.02 \pm 1.53$ & $<0.001$ \\
\hline \multicolumn{4}{|l|}{ Quality of cryopreserved embryos } \\
\hline - Good & $1213(86.8 \%)$ & $1421(77.6 \%)$ & \\
\hline - Fair & $135(9.7 \%)$ & $276(15.1 \%)$ & $<0.001$ \\
\hline Cancellation rate & $5(0.8 \%)$ & $9(0.5 \%)$ & 0.376 \\
\hline Implantation rate per cycle & $0.43 \pm 0.48$ & $0.35 \pm 0.50$ & $<0.001$ \\
\hline Biochemical pregnancies & $39(6.1 \%)$ & $135(7.5 \%)$ & 0.254 \\
\hline Clinical pregnancy rate & $318(49.9 \%)$ & $733(40.6 \%)$ & $<0.001$ \\
\hline Singleton pregnancies & $236(37 \%)$ & $532(29.5 \%)$ & $<0.001$ \\
\hline Multiple pregnancies & $33(5.2 \%)$ & $80(4.4 \%)$ & 0.438 \\
\hline Ectopic pregnancies & $2(0.3 \%)$ & $14(0.8 \%)$ & 0.266 \\
\hline Miscarriages & $49 / 318(15.4 \%)$ & $121 / 733(16.5 \%)$ & 0.911 \\
\hline Live birth rate & $302(45.1 \%)$ & $692(36.7 \%)$ & $<0.001$ \\
\hline
\end{tabular}

IVF: In-vitro fertilization; hCG: Human chorionic gonadotropin.

TABLE 3: Independent variables effecting implantation rates revealed by multivariate linear regression analysis with backward elimination.

\begin{tabular}{|lcc|}
\hline & p value & Beta (\%95 confidence interval) \\
\hline Age & $<0.001$ & $-0.016[(-0.020)-(-0.012)]$ \\
Number of 2 pronuclear embryo & $<0.001$ & $0.017(0.011-0.024)$ \\
Embryo quality & $<0.001$ & $-0.20[(-0.25)-(-0.15)]$ \\
\hline
\end{tabular}

TABLE 4: Multivariate logistic regression analysis for the prediction of live births.

\begin{tabular}{|lcc|}
\hline & p value & Odds ratio (\%95 confidence interval) \\
\hline Age & $<0.001$ & $0.953(0.936-0.970)$ \\
\hline Dual trigger $(+)$ & 0.005 & $1.426(1.185-1.716)$ \\
\hline Fertilization rate & $<0.001$ & $3.237(2.074-5.053)$ \\
\hline Maturation rate & 0.016 & $1.786(1.115-2.860)$ \\
\hline
\end{tabular}




\section{DISCUSSION}

In the present study, we found that dual-triggering in $\mathrm{GnRH}$ antagonist cycles are associated with a significant increase in clinical pregnancy rates and live birth rates in women with expected normal ovarian response. These results might be consequences of increased oocyte maturation, increased embryo quality and increased endometrial receptivity or a combination of these factors.

GnRH agonists induce a surge of both FSH and LH from pituitary with flare-up effects. In a previous study, Lamb et al. demonstrated FSH administration at the time of hCG triggering improves oocyte's developmental competence, oocyte retrieval and number of 2PN embryos in IVF cycles..$^{30}$ Although the role of FSH in oocyte maturation is not yet completely understood. It has been shown that FSH induces LH receptor formation on granulosa cells, along with increasing the expression of amphiregulin and epiregulin that take place in cumulus expansion and resumption of meiosis. ${ }^{31}$ Besides the effects of FSH, dual-triggering causes surge of LH while hCG only mimics LH by binding the same $\mathrm{LH}$ receptor as previously mentioned. Studies demonstrated that although LH and hCG bind to same LH receptor, they activate different downstream signal transduction pathways. ${ }^{1,3} \mathrm{LH} / \mathrm{LH}$ receptor binding primarily stimulates phosphorylation of AKT and extracellular signal-regulated kinase $1 / 2$ that take part in granulosa cell proliferation, whereas $\mathrm{hCG} / \mathrm{LH}$ receptor binding causes a higher intracellular cyclic adenosine monophosphate accumulation that induce steroidogenesis. ${ }^{1,3}$ Furthermore, presence of GnRH receptors are demonstrated on human granulosa cells in antral follicles and $\mathrm{GnRH} / \mathrm{GnRH}$ receptor interaction is found associated with follicular development and corpus luteum functions. ${ }^{32}$ Increased number of M2 oocytes retrieved in normal responder women underwent cycles with dual triggering has been demonstrated in some previous studies. ${ }^{21,23,33}$ Griffin et al. showed that dual-triggering is associated with increased oocyte maturation rates. ${ }^{9}$ Although, some authors found increased number of M2 oocytes retrieved in dual triggered normo-responder women in their studies, differences have not reached statistical significance probably due to smaller sample size of these studies. ${ }^{5,10,17,24}$ Parallel with literature, we found higher number of retrieved oocytes, higher number of M2 oocytes and higher rate of oocyte maturation in our study.

GnRH receptor cells have also been demonstrated to exist on human endometrial cells and evidence indicate that these receptors have a possible role in endometrial receptivity. ${ }^{32}$ A study conducted by Rackow et al. revealed a dose dependent reduction in endometrial HOXA10 expression in GnRH antagonist cycles. HOXA10 is a crucial regulator of endometrial receptivity and they suggested that administration of GnRH antagonists could be associated with decreased endometrial receptivity. ${ }^{34}$ Supporting this suggestion, some other studies demonstrated increased expression of HOXA10 and HOXA11 along with improved endometrial receptivity with GnRH agonist administration. ${ }^{7,8}$ We found increased endometrial thickness and higher implantation rates in women to whom GnRH agonist along with hCG was administered for oocyte maturation. However multivariate linear regression analysis in our study identified age, number of 2PN embryos and embryo quality as independent determinants of implantation, whereas triggering method was not found independently associated with implantation rate. These findings imply that dual trigger primarily increase implantation rates via increasing number of 2PN embryos and embryo quality. It seems dubious that a single dose of $0.2 \mathrm{mg}$ triptorelin acetate administration along with hCG injection 6 days before embryo transfer improves endometrial receptivity to a clinically significant extent in women with expected normal ovarian response.

Some previous studies mentioned a negative impact of hCG on embryo quality and GnRH agonist administration is suggested to improve embryo quality. ${ }^{6,35}$ In this study, we found increased total obtained embryo quality in dual-triggering group as substantiated with higher rate of clinical pregnancies and live birth deliveries in this group. Aligning with our findings, some recent studies indicated that dual-triggering was associated with higher embryo quality in normo-reponders that underwent GnRH antagonist cycles. ${ }^{5,10,25}$

Among the currently available studies conducted about dual-triggering in normo-reponder women that 
reported early pregnancy losses, none of them have shown a significant difference in miscarriage rates..$^{10,21,23,25}$ Similarly, we found equivalent rates of miscarriages in women with expected normal ovarian response underwent $\mathrm{GnRH}$ antagonist cycles with dual-triggering in comparison to hCG-only triggering.

Although growing number of studies in literature indicate better IVF outcomes in normal responder women underwent GnRH antagonist cycles with dual-triggering, current level of evidence is not adequate to clearly recommend dual-triggering over hCG-only triggering in this group of patients. ${ }^{23,26} \mathrm{In}$ this retrospective cohort study, we demonstrated clinical pregnancy rates and live birth rates are significantly higher in dual-triggering group in comparison to hCG-only group among women with expected normal ovarian response probably due to accumulative effects of increased oocyte maturation and higher embryo quality.

In our study, mean numbers of cryopreserved embryos per cycle in dual-triggering group and hCGonly group were $2.21 \pm 1.5$ and $1.02 \pm 1.53$, respectively. The difference was statistically significant. We also found that the quality of cryopreserved embryos were significantly increased in dual-triggering group compared to hCG-only group in patients with expected normal ovarian response. Although we only evaluated the results of fresh embryo transfers, considering the higher number and quality of surplus embryos that were cryopreserved, dual-triggering could expected to cause an even greater increase in cumu- lative rates of clinical pregnancies and live birth deliveries whenever frozen embryo transfers are required in these patients due to initial failures in achieving pregnancy following fresh embryo transfers.

\section{CONCLUSION}

In conclusion, dual triggering appears to improve embryo quality, increase implantation rates, clinical pregnancies and live birth deliveries in women with expected normal ovarian response that underwent GnRH antagonist cycles.

\section{Source of Finance}

During this study, no financial or spiritual support was received neither from any pharmaceutical company that has a direct connection with the research subject, nor from a company that provides or produces medical instruments and materials which may negatively affect the evaluation process of this study.

\section{Conflict of Interest}

No conflicts of interest between the authors and / or family members of the scientific and medical committee members or members of the potential conflicts of interest, counseling, expertise, working conditions, share holding and similar situations in any firm.

\section{Authorship Contributions}

Idea/Concept: Firat Tülek; Design: Alper Kahraman; Control/Supervision: Fırat Tülek, Alper Kahraman; Data Collection and/or Processing: Firat Tülek; Analysis and/or Interpretation: Firat Tülek, Alper Kahraman; Literature Review: Alper Kahraman; Writing the Article: Alper Kahraman, Firat Tülek; Critical Review: Firat Tülek; Materials: Fırat Tülek

\section{REFERENCES}

1. Orvieto $R$. Triggering final follicular maturation-hCG, GnRH-agonist or both, when and to whom? J Ovarian Res. 2015;8:60. [Crossref] [Pubmed] [PMC]

2. Gonen Y, Balakier H, Powell W, Casper RF. Use of gonadotropin-releasing hormone agonist to trigger follicular maturation for in vitro fertilization. J Clin Endocrinol Metab. 1990; 71(4):918-22. [Crossref] [Pubmed]

3. Casarini L, Lispi M, Longobardi S, Milosa F, La Marca A, Tagliasacchi D, et al. LH and hCG action on the same receptor results in quanti- tatively and qualitatively different intracellular signalling. PLoS One. 2012;7(10): e46682. [Crossref] [Pubmed] [PMC]

4. Kol S, Humaidan P. GnRH agonist triggering: recent developments. Reprod Biomed Online. 2013;26(3):226-30. [Crossref] [Pubmed]

5. Haas J, Bassil R, Samara N, Zilberberg E, Mehta C, Orvieto R, et al. GnRH agonist and hCG (dual trigger) versus hCG trigger for final follicular maturation: a double-blinded, randomized controlled study. Hum Reprod. 2020;35(7):1648-54. [Crossref] [Pubmed]
6. Youssef MA, Van der Veen F, Al-Inany HG, Mochtar MH, Griesinger G, Nagi Mohesen M, et al. Gonadotropin-releasing hormone agonist versus HCG for oocyte triggering in antagonist-assisted reproductive technology. Cochrane Database Syst Rev. 2014;(10): CD008046. [Crossref] [Pubmed]

7. Guo S, Li Z, Yan L, Sun Y, Feng Y. GnRH agonist improves pregnancy outcome in mice with induced adenomyosis by restoring endometrial receptivity. Drug Des Devel Ther. 2018;12:1621-31. [Crossref] [Pubmed] [PMC] 
8. Tesarik J, Hazout A, Mendoza C. Enhancement of embryo developmental potential by a single administration of $\mathrm{GnRH}$ agonist at the time of implantation. Hum Reprod. 2004;19(5): 1176-80. [Crossref] [Pubmed]

9. Griffin D, Feinn R, Engmann L, Nulsen J, Budinetz T, Benadiva C. Dual trigger with gonadotropin-releasing hormone agonist and standard dose human chorionic gonadotropin to improve oocyte maturity rates. Fertil Steril. 2014;102(2):405-9. [Crossref] [Pubmed]

10. Şükür YE, Ulubaşoğlu H, IIIhan FC, Berker B, Sönmezer M, Atabekoğlu CS, et al. Dual trigger in normally-responding assisted reproductive technology patients increases the number of top-quality embryos. Clin Exp Reprod Med. 2020;47(4):300-5. [Crossref] [Pubmed] [PMC]

11. Kim CH, Ahn JW, You RM, Kim SH, Chae HD, Kang BM. Combined administration of gonadotropin-releasing hormone agonist with human chorionic gonadotropin for final oocyte maturation in $\mathrm{GnRH}$ antagonist cycles for in vitro fertilization. J Reprod Med. 2014;59(12):63-8. [Pubmed]

12. Benadiva C, Engmann L. Luteal phase support after gonadotropin-releasing hormone agonist triggering: does it still matter? Fertil Steril. 2018;109(5):763-7. [Crossref] [Pubmed]

13. Shapiro BS, Daneshmand ST, Garner FC, Aguirre M, Thomas S. Gonadotropin-releasing hormone agonist combined with a reduced dose of human chorionic gonadotropin for final oocyte maturation in fresh autologous cycles of in vitro fertilization. Fertil Steril. 2008;90(1): 231-3. [Crossref] [Pubmed]

14. Griffin D, Benadiva C, Kummer N, Budinetz T, Nulsen J, Engmann L. Dual trigger of oocyte maturation with gonadotropin-releasing hormone agonist and low-dose human chorionic gonadotropin to optimize live birth rates in high responders. Fertil Steril. 2012;97(6):1316-20. [Crossref] [Pubmed]

15. Maged AM, Ragab MA, Shohayeb A, Saber W, Ekladious S, Hussein EA, et al. Comparative study between single versus dual trigger for poor responders in $\mathrm{GnRH}$-antagonist ICSI cycles: A randomized controlled study. Int J Gynaecol Obstet. 2021;152(3):395-400. [Crossref] [Pubmed]

16. Lin MH, Wu FS, Hwu YM, Lee RK, Li RS, Li $\mathrm{SH}$. Dual trigger with gonadotropin releasing hormone agonist and human chorionic gonadotropin significantly improves live birth rate for women with diminished ovarian reserve. Reprod Biol Endocrinol. 2019;17(1):7. [Crossref] [Pubmed] [PMC]

17. Decleer W, Osmanagaoglu K, Seynhave B, Kolibianakis S, Tarlatzis B, Devroey P. Com- parison of $h C G$ triggering versus $\mathrm{hCG}$ in combination with a $\mathrm{GnRH}$ agonist: A prospective randomized controlled trial. Facts Views Vis Obgyn. 2014;6(4):203-9. [Pubmed] [PMC]

18. Chern CU, Li JY, Tsui KH, Wang PH, Wen ZH, Lin LT. Dual-trigger improves the outcomes of in vitro fertilization cycles in older patients with diminished ovarian reserve: A retrospective cohort study. PLoS One. 2020;15(7):e023 5707. [Crossref] [Pubmed] [PMC]

19. Li S, Zhou D, Yin T, Xu W, Xie Q, Cheng D, et al. Dual trigger of triptorelin and HCG optimizes clinical outcome for high ovarian responder in $\mathrm{GnRH}$-antagonist protocols. Oncotarget. 2018:9(4):5337-43. [Crossref] [Pubmed] [PMC]

20. Eser A, Devranoğlu B, Bostancı Ergen E, Yayla Abide Ç. Dual trigger with gonadotropinreleasing hormone and human chorionic gonadotropin for poor responders. J Turk Ger Gynecol Assoc. 2018;19(2):98-103. [Crossref] [Pubmed] [PMC]

21. Lin MH, Wu FS, Lee RK, Li SH, Lin SY, Hwu YM. Dual trigger with combination of gonadotropin-releasing hormone agonist and human chorionic gonadotropin significantly improves the live-birth rate for normal responders in $\mathrm{GnRH}$-antagonist cycles. Fertil Steril. 2013;100(5):1296-302. [Crossref] [Pubmed]

22. Eftekhar M, Mohammadi B, Khani P, Lahijani MM. Dual stimulation in unexpected poor responder POSEIDON classification group 1, sub-group 2a: A cross-sectional study. Int J Reprod Biomed. 2020;18(6):465-70. [Crossref] [Pubmed] [PMC]

23. Ali SS, Elsenosy E, Sayed GH, Farghaly TA, Youssef AA, Badran E, et al. Dual trigger using recombinant HCG and gonadotropin-releasing hormone agonist improve oocyte maturity and embryo grading for normal responders in GnRH antagonist cycles: Randomized controlled trial. J Gynecol Obstet Hum Reprod. 2020;49(5):101728. [Crossref] [Pubmed]

24. Seval MM, Özmen B, Atabekoğlu C, Şükür YE, Şimşir C, Kan Ö, et al. Dual trigger with gonadotropin-releasing hormone agonist and recombinant human chorionic gonadotropin improves in vitro fertilization outcome in gonadotropin-releasing hormone antagonist cycles. J Obstet Gynaecol Res. 2016;42(9): 1146-51. [Crossref] [Pubmed]

25. Zhou X, Guo P, Chen X, Ye D, Liu Y, Chen S. Comparison of dual trigger with combination $\mathrm{GnRH}$ agonist and $\mathrm{hCG}$ versus $\mathrm{hCG}$ alone trigger of oocyte maturation for normal ovarian responders. Int J Gynaecol Obstet. 2018;141(3):327-31. [Crossref] [Pubmed]

26. Ovarian Stimulation TEGGO, Bosch E, Broer $S$, Griesinger G, Grynberg M, Humaidan P, et al. ESHRE guideline: ovarian stimulation for IVF/ICSI†. Hum Reprod Open. 2020;2020(2): hoaa009. Erratum in: Hum Reprod Open. 2020;2020(4):hoaa067. [Crossref] [Pubmed] [PMC]

27. Humaidan $P$, Alviggi $C$, Fischer R, Esteves SC. The novel POSEIDON stratification of 'Low prognosis patients in Assisted Reproductive Technology' and its proposed marker of successful outcome. F1000Res. 2016;5: 2911. [Crossref] [Pubmed] [PMC]

28. Racowsky C, Vernon M, Mayer J, Ball GD, Behr B, Pomeroy KO, et al. Standardization of grading embryo morphology. J Assist Reprod Genet. 2010;27(8):437-9. [Crossref] [Pubmed] [PMC]

29. Zegers-Hochschild F, Adamson GD, Dyer S, Racowsky C, de Mouzon J, Sokol R, et al. The international glossary on infertility and fertility care, 2017. Fertil Steril. 2017;108(3):393-406. [Crossref] [Pubmed]

30. Lamb JD, Shen S, McCulloch C, Jalalian L, Cedars MI, Rosen MP. Follicle-stimulating hormone administered at the time of human chorionic gonadotropin trigger improves oocyte developmental competence in in vitro fertilization cycles: a randomized, double-blind, placebo-controlled trial. Fertil Steril. 2011; 95(5):1655-60. [Crossref] [Pubmed]

31. Haas J, Ophir L, Barzilay E, Machtinger R, Yung $Y$, Orvieto R, et al. Standard human chorionic gonadotropin versus double trigger for final oocyte maturation results in different granulosa cells gene expressions: A pilot study. Fertil Steril. 2016;106(3):653-9.e1. [Crossref] [Pubmed]

32. Maggi R, Cariboni AM, Marelli MM, Moretti RM, Andrè V, Marzagalli M, et al. GnRH and $\mathrm{GnRH}$ receptors in the pathophysiology of the human female reproductive system. Hum Reprod Update. 2016;22(3):358-81. [Crossref] [Pubmed]

33. Schachter M, Friedler S, Ron-El R, Zimmerman AL, Strassburger D, Bern O, et al. Can pregnancy rate be improved in gonadotropinreleasing hormone $(\mathrm{GnRH})$ antagonist cycles by administering $\mathrm{GnRH}$ agonist before oocyte retrieval? A prospective, randomized study. Fertil Steril. 2008;90(4):1087-93. [Crossref] [Pubmed]

34. Rackow BW, Kliman HJ, Taylor HS. GnRH anagonists may affect endometrial receptivity. Fertil Steril. 2008;89(5):1234-9. [Crossref] [Pubmed] [PMC]

35. Lan KC, Chen YC, Lin YC, Tsai YR. Gonadotrophin-releasing hormone agonist triggering may improve central oocyte granularity and embryo quality. Zygote. 2020;28(4):33743. [Crossref] [Pubmed] 